\title{
The epidemiological study of congenital anomalies and their possible risk factors in teaching hospital in MGM Kalamboli, Navi Mumbai
}

\author{
Vidya Kamble, Shaifali Patil, Tulsi Bhatia, Pradnya Thaware*, Pushpa Mathur
}

Department of Obstetrics \& Gynaecology, MGM Medical College \& Hospital, Kalamboli, Navi Mumbai

Received: 24 July 2015

Accepted: 17 August 2015

\author{
*Correspondence: \\ Dr Pradnya Thaware, \\ E-mail: pradnyathaware20@gmail.com
}

Copyright: () the author(s), publisher and licensee Medip Academy. This is an open-access article distributed under the terms of the Creative Commons Attribution Non-Commercial License, which permits unrestricted non-commercial use, distribution, and reproduction in any medium, provided the original work is properly cited.

\begin{abstract}
Background: Congenital anomaly, a health problem in India, is a defective morphogenesis during early foetal life at cellular level. Purpose of our study was to determine the detection rate of congenital anomalies \& their epidemiological predisposing risk factors with detailed history withdrawn among women visited in MGM Hospital, Kalamboli, Navi Mumbai, between May 2012 to May 2014.

Methods: This is a Retrospective study. In this study period of 2 years, 69 pregnant women were diagnosed with congenital anomalies during their prenatal Ultrasonographic examinations. We studied these sonographic reports with the risk factors associated with occurrence of congenital anomalies.

Results: Out of 2000 visited women, 69 were detected with congenital anomalies. Incidence rate was about $3.45 \%$. Major \&maximum anomalies were found in CNS \& Renal system. CNS-32.88\%, renal-40.58\%, multiple system anomalies-5.79\%. Risk factors mostly associated with these anomalies were age, race, residency, social status, H/O consanguineous marriage, H/O DM \& GDM, literacy. Congenital anomalies were more seen in rural, low socioeconomic \& illiterate population.

Conclusions: Early diagnosis, prenatal evaluation, routine ANC care, better repo \& good quality USG will be helpful for genetic counselling \& clinical management.
\end{abstract}

Keywords: Congenital anomalies, Epidemiological risk factors, Prenatal evaluation, Early diagnosis

\section{INTRODUCTION}

Congenital anomalies comprise $8 \%$ of perinatal mortality in India. Congenital anomaly is a defective morphogenesis during early foetal life. A broader definition includes metabolic \& microscopic defects at cellular level. This is now the global health problem in India. Every year as estimated 7.9 million children are born with serious defects, 3.3 million children die from birth defects \& 3.2 million children who survive develops disability in later life. ${ }^{1}$ At present invasive prenatal diagnostic test continue to be the gold standard for pregnancies which are at increased risk to have congenital anomaly. International organisations have been established to conduct worldwide surveillance \& research into occurrence \& possible causes of congenital anomalies \& to establish prevention strategies. ${ }^{2}$ This is the leading cause of prenatal \& childhood morbidity \& disability in many countries.

Our study was an attempt to detect the incidence of congenital anomalies by ultrasound \& risk factors associated with their occurrences among women who visited MGM hospital from May 2012 to May 2014. From this study we should evaluate possible risk factors $\&$ to implement effective prevention \& care services. This information is also important for planning \& performing antenatal screening for these anomalies particularly to high risk population. 
The aim of our study was to determine epidemiological risk factors of congenital anomalies according toage, residence, social status, literacy, consanguineous marriages, family history, drug history, alcohol addiction, DM \& GDM history.

Pregnancy outcome was decided after paediatric surgeon's opinion divided into: 1) Termination of pregnancy in cases diagnosed before 20 weeks with major congenital anomalies. 2) Continuation of pregnancy with live birth with minor congenital anomalies. Follow up investigations done where necessary up to 2 weeks of postnatal days.

\section{METHODS}

Place of study: Department Of Obstetrics \& Gynaecology, MGM Hospital Kalamboli, Navi Mumbai.

Study: Retrospective study.

Duration of study: May 2012 to May 2014.

Study population: 69 pregnant women with congenital anomalies \& their risk factors.

\section{Inclusion criteria}

Any pregnant female in any trimester of pregnancy in any system, single \& multiple anomalies in any gestational age of pregnancy with diagnosis of congenital anomalies.

\section{RESULTS}

Statistical analysis among 69 pregnant women according to their following risk factors:-

Table 1: Age: With increasing age higher chances of congenital anomalies.

\begin{tabular}{|lll|}
\hline Age (years) & No. & Percentage \\
\hline $\mathbf{2 0 - 2 5}$ & 28 & $40.50 \%$ \\
\hline $\mathbf{2 6 - 3 0}$ & 38 & $55 \%$ \\
\hline$>\mathbf{3 0}$ & 03 & $4.50 \%$ \\
\hline Total & 69 & $100 \%$ \\
\hline
\end{tabular}

Table 2: Residence: rural population more prone for these congenital anomalies as compared to urban population.

\begin{tabular}{|lll|}
\hline Residence & No. & Percentage \\
\hline Urban & 17 & $24.64 \%$ \\
\hline Rural & 52 & $75.36 \%$ \\
\hline Total & 69 & $100 \%$ \\
\hline
\end{tabular}

Table 3: Literacy: illiteracy is also major risk factor for congenital anomalies.

\begin{tabular}{|lll|}
\hline Literacy status & No. & Percentage \\
\hline Literate & 27 & $39.13 \%$ \\
\hline Illiterate & 42 & $60.87 \%$ \\
\hline Total & 69 & $100 \%$ \\
\hline
\end{tabular}

Table 4: Consanguineous marriage: their high chances of congenital malformation in consanguineous marriages.

\begin{tabular}{|lll|}
\hline $\begin{array}{l}\text { Consanguinous } \\
\text { marriage }\end{array}$ & No. & Percentage \\
\hline YES & 09 & $13.04 \%$ \\
\hline NO & 60 & $86.96 \%$ \\
\hline Total & 69 & $100 \%$ \\
\hline
\end{tabular}

Table 5: System involved.

\begin{tabular}{|lll|}
\hline System & No. & Percentage \\
\hline CNS & 22 & $31.88 \%$ \\
\hline RS & 00 & $00.00 \%$ \\
\hline Renal & 28 & $40.58 \%$ \\
\hline CVS & 06 & $8.70 \%$ \\
\hline Liver & 01 & $1.45 \%$ \\
\hline GIT & 01 & $1.45 \%$ \\
\hline $\begin{array}{l}\text { Circulatory(2vessel in } \\
\text { cord) }\end{array}$ & 03 & $4.35 \%$ \\
\hline Skeleton & 03 & $4.35 \%$ \\
\hline OMFS(cleft lip) & 01 & $1.45 \%$ \\
\hline Multiple systems & 04 & $5.79 \%$ \\
\hline TOTAL & 69 & $100 \%$ \\
\hline
\end{tabular}

Table 6: Social status: low social population more prone for these congenital anomalies.

\begin{tabular}{|lll|}
\hline Social status & No. & Percentage \\
\hline L.C & 49 & $71.01 \%$ \\
\hline M.C & 17 & $24.64 \%$ \\
\hline H.C & 03 & $4.35 \%$ \\
\hline Total & 69 & $100 \%$ \\
\hline
\end{tabular}

Women having H/O Diabetes have more chances for congenital anomalies. In our study 1 case has $\mathrm{H} / \mathrm{O}$ Diabetes. H/O any addiction like any drug or alcohol, in this study 2 cases had alcohol addiction. In this study Hindu population are mostly involved having the highest percentage.

\section{DISCUSSION}

This study was a Retrospective study to determine incidence of congenital anomalies \& their associated epidemiological risk factors associated with occurrence among women visited at MGM hospital Kalamboli, Navi Mumbai.

Our study is compared with various other previous studies on similar topics.

Incidence of congenital anomalies in various studies is low $1.6 \%$ as compared to present study which is $3.45 \%$. However, the study of Bhat et al had an incidence of $3.7 \%$ 
Table 7: The result compared with other countries.

\begin{tabular}{|ll|}
\hline COUNTRY & $\begin{array}{l}\text { Incidence of congenital } \\
\text { anomalies }\end{array}$ \\
\hline China & $1.1 \%$ \\
\hline Russia & $1.23 \%$ \\
\hline UAE & $1.5 \%$ \\
\hline England & $2 \%$ \\
\hline United states & $2.3 \%$ \\
\hline
\end{tabular}

Table 8: Incidence of congenital anomalies in various studies compared with our present study.

\begin{tabular}{|ll|}
\hline STUDY & Percentage of incidence \\
\hline Aggrawal SS et al 1991 & $1.6 \%$ \\
\hline Bhat BV et al 1998 & $3.7 \%$ \\
\hline Patel ZM et al 2005 & $1.6 \%$ \\
\hline $\begin{array}{l}\text { Present study } \quad \mathbf{2 0 1 2}^{\mathbf{5}} \\
\text { 2014) }\end{array}$ & $3.4 \%$ \\
\hline
\end{tabular}

This wide variation due to various factors such as population sample, geographic \& social group differences, different age groups. This variation might also be due to various epidemiological factors like age, socioeconomicalstatus, religion, residence, family history, illiteracy, consanguineous marriages, DM \& GDM history, any drug history, alcohol addiction, gestational age of diagnosis. It may also be due to fact that this is referral institute $\&$ more cases with congenital anomalies were referred from periphery.

According to WHO, incidence of congenital anomalies are more in lower socioeconomic status. This could be because of poor nutrition, poor hygiene, illiteracy, poor living status, no folic acid intake during first trimester \& no antenatal check-up including timely USG during pregnancy.

CNS System was the most commonly involved (31.88\%). This is compared with studies by Neelam \& Grover et al. It is relatively higher. In Central nervous system, most common anomalies were anencephaly, meningocoele \& hydrocephalus.

Renal system was also commonly involved (40.58\%) in our study but morbidity \& mortality rate in this system is relatively low.

Third most involved system is cardiovascular system $(8.70 \%)$. Multiple system involved rarely found were Dandy Walker Syndrome, Prune Belly Syndrome.

There also involved other systems like hepatic (1 case), GIT (1 case), Circulatory system (3 cases), Skeleton (3 cases), OMFS (cleft lip) (1 case).

There is increased risk of congenital anomalies with increasing age, low socioeconomic group, illiterate women, rural population, consanguineous marriages, and addiction like alcohol, drugs and women with DM \& GDM. In the present study, maximum number of congenital anomalies was observed in age group 25-30 years. This similar observation was made by Kulshresha et al. Sugunbai reported a higher incidence of congenital anomalies in babies born to mother aged over 35 years. ${ }^{6}$ Datta et al. documented statistically insignificant association of increased mother age \& congenital anomalies. $^{7}$

\section{CONCLUSIONS}

MGM Hospital is the referral centre for many rural areas, low social people \& aadiwasi areas surrounding in Raigad district. Congenital anomalies pose a threat for survival of new born in early neonatal period. Prevention of congenital anomalies can be achieved by proper marriage counselling for avoiding early \& consanguineous marriages, proper nutrition \& proper education to pregnant women, early ANC registration, periconceptional folate consumption should be advised during the marriage counselling itself sothat parents understand the need for the same when they plan for an issue.

During pregnancy, especially during first trimester mother should be advised to avoid drugs, irradiation, chemical \& infection which act as teratogenic. Regular antenatal check-up \& ultrasound scan NT, NB scan for high risk patients around 9-11 weeks \& congenital anomaly scan around $18-22$ weeks to rule out gross congenital anomaly. Screening for high risk mothers first \& then subject to undergo investigations like high resolution ultrasound, amniocentesis, chorionic villi sampling wherever required. Efforts should be taken to make diagnosis of congenital anomalies early so that referral can be made at earliest for early intervention \& transfer can be made by paediatric surgeon at an appropriate centre. Whenever genetic etiologyis suspected parents should be referred to genetic counsellor after confirmation the diagnosis by appropriate method like karyotyping.

Economical \& psychological burden of parents with anomalous babies are beyond all imagination so a Rational \& multidisciplinary approach with good communication between various specialities like Obstetrician, radiologist, genetist, pathologist, paediatrician, parents, Asha workers \& PHC centres is essential.

Best effort should be put to make the diagnosis of congenital anomaly early so that referral can be made at the earliest for early intervention \& planned delivery at appropriate hospital.

\section{Funding: No funding sources \\ Conflict of interest: None declared}

Ethical approval: The study was approved by the Institutional Ethics Committee 


\section{REFERENCES}

1. Carmona RH. The global challenge of birth defects \& disabilities. The lancet. 2005;366(9422):1142-4.

2. International Clearinghouse for Birth Defects Monitoring Systems, Annual report 2005: with data for 2003, Roma, Italy, 2005.

3. Aggrawal SS, Singh U, Singh PS, Singh SS, Das V, Sharma A, et al. Prevalence and spectrum of congenital malformations in a prospective study at teaching hospital. India J Med Res. 1991;94:413.

4. Bhat BV, RaviKumara M. Perinatal mortality in India: need for introspection. Indian $\mathbf{J}$ of Maternal and Child Health. 1996;7:31-3.
5. Patel ZM, Adhia RA. Birth defects surveillance study. Indian J Pediatr. 2005;72:489-91.

6. Suguna Bai NS, Mascarene M, Syamala K, Nair PM. An etiological study of congenital malformation in the new born. Indian Pediatr. 1982;19:1003-7.

7. Datta V, Chaturvedi P. Congenital malformations in rural Maharashtra. India Pediatr 2000;37:998-1001.

Cite this article as: Kamble V, Patil S, Bhatia T, Thaware P, Mathur P. The epidemiological study of congenital anomalies and their possible risk factors in teaching hospital in MGM Kalamboli, Navi Mumbai. Int J Reprod Contracept Obstet Gynecol 2015; 4:1396-9. 